\title{
EFEITO DO USO DO NITRATO E NITRITO NA INIBIÇÃO DE Clostridium perfringens TIPO A EM LINGÜIÇA BOVINA CURADA
}

\author{
MELISSA AMIN* \\ JAIR VICENTE OLIVEIRA**
}

\begin{abstract}
O presente trabalho teve como objetivo verificar a eficiência dos conservantes nitrato e nitrito na inibição do Clostridium perfringens tipo A, (responsável por toxinfecção alimentar) durante a vida útil de lingüiças de carne bovina curadas. As amostras foram elaboradas partindo-se de massa subdividida em grupo controle e grupo tratamento (adicionado de sal de cura), ambos inoculados com a cultura de $C$. perfringens $(6 \mathrm{x}$ $10^{3}$ UFC). Efetuaram-se análises microbiológicas para quantificação da bactéria e a determinação dos níveis residuais de nitrato e nitrito. Os resultados demonstraram que durante o período de vida útil do produto (44 dias) não houve desenvolvimento do microrganismo nas lingüiças que receberam tratamento, mesmo em níveis baixos de nitrato e nitrito. Já no grupo controle verificou-se crescimento do microrganismo, embora enquadrado no limite exigido pela legislação brasileira ( $3 \times 10^{3}$ UFC). As quantidades de nitrato e nitrito de sódio adicionadas (200 ppm) indicaram período de redução dos níveis de no mínimo quatro dias após o processo de elaboração, permanecendo então abaixo dos limites permitidos pela legislação (150 ppm). Os resultados obtidos evidenciaram a eficiência dos conservantes nitrato e nitrito na inibição do microrganismo Clostridium perfringens tipo A em lingüiça.
\end{abstract}

PALAVRAS-CHAVE: NITRATO; NITRITO; Clostridium perfringens; LINGÜIÇA.

Médica Veterinária, Mestre em Ciência Animal, Professora Colaboradora, Departamento de Tecnologia de Alimentos e Saúde Pública (DTASP), Universidade Federal de Mato Grosso do Sul (UFMS), Campo Grande, MS (e-mail: amin.msi@terra.com.br).

** Médico Veterinário, Doutor em Tecnologia de Alimentos, Professor Adjunto, DTASP, UFMS, Campo Grande, MS (e-mail: jvicente@nin.ufms.br).

B.CEPPA, Curitiba v. 24, n. 1, p. 13-24 jan./jun. 2006 


\section{INTRODUÇÃO}

Desde a Antigüidade, o homem fabrica diferentes tipos de lingüiça na busca de conservar a carne e fornecer produto agradável ao consumidor (TERRA, 1998).

A lingüiça é o produto cárneo industrializado, elaborado a partir de carnes de animais de açougue, adicionado ou não de tecidos adiposos, ingredientes, embutido em envoltório natural ou artificial e submetido a processo tecnológico adequado (BRASIL, 2000). É classificada como produto curado e embutido, na subcategoria 8.2.1.1, da Portaria n¹002 da Agência Nacional de Vigilância Sanitária do Ministério da Saúde (BRASIL, 1998b).

Segundo FERNANDEZ, CASTRO e BECKER (2005), a ausência de critérios na elaboração da lingüiça pode implicar em riscos para o consumidor, sejam eles higiênico-sanitários ou pelo uso excessivo de aditivos.

Os aditivos considerados como ingredientes principais da cura e que têm sido comumente utilizados na indústria como conservantes de produtos cárneos são o nitrato e o nitrito (HAYES, 1993; PINHO et al., 1998; ÖZTEKIN, NUTKU e ERIM, 2002; SOARES et al., 2003). Para JAY (1994), além de seu efeito antimicrobiano contra o Clostridium botulinum, o nitrito também se mostra eficaz em relação a outros clostrídios, como o patogênico Clostridium perfringens.

BRYNESTAD e GRANUM (2002) afirmaram que o microrganismo $C$. perfringens tipo $A$ provoca intoxicação alimentar nos locais em que se preparam grande quantidade de alimentos resfriados lentamente, ou insuficientemente reaquecidos. Basta a ingestão de cerca de $10^{7}$ células bacterianas para existir a possibilidade da toxinfecção ocorrer em humanos.

O processamento inadequado aumenta a multiplicação bacteriana e os esporos de $C$. perfringens tipo A sobreviventes ao processo é que são responsáveis pela gastroenterite decorrente da produção de enterotoxina no intestino delgado.

Devido ao tempo curto de duração dos sintomas, cerca de 24 horas, a maioria das pessoas não entra em contato com as autoridades 
sanitárias e o número de casos não é corretamente estimado. De acordo com CÂMARA (2002), no estado de Mato Grosso do Sul, o microrganismo $C$. perfringens representou $12,8 \%$ dos surtos de toxinfecções alimentares no período de 1998 a 2001.

O presente trabalho avaliou o uso do nitrato e nitrito inoculado para a inibição de $C$. perfringens tipo $\mathrm{A}$ em lingüiça bovina curada.

\section{MATERIAL E MÉTODOS}

As amostras de lingüiças foram elaboradas no Laboratório de Tecnologia de Produtos de Origem Animal, Departamento de Tecnologia de Alimentos e Saúde Pública (DTASP), Universidade Federal de Mato Grosso do Sul (UFMS), segundo Boas Práticas de Fabricação (BPF) e de acordo com a legislação específica (BRASIL, 1997).

A linhagem do microrganismo Clostridium perfringens tipo A, origem ATCC 3624, foi reidratada segundo metodologia oficial (BRASIL, 2005), utilizando-se o meio Reinforced Clostridium Medium (RCM). Após a reidratação, a cultura foi ativada em meio Fluido Tioglicolato.

Para a elaboração das lingüiças foi utilizada a formulação descrita na Tabela 1.

\section{TABELA 1 - FORMULAÇÃO DAS LINGÜIÇAS BOVINAS}

\begin{tabular}{lcc}
\hline \multicolumn{1}{c}{ Formulação } & \multicolumn{2}{c}{ Quantidade (kg) } \\
\cline { 2 - 3 } & Grupo Controle & Grupo Tratamento \\
\hline Came bovina & 1,745 & 1,745 \\
(contra filé = Longissimus dorsı) & 0,3079 & 0,3079 \\
Toucinho & 0,0349 & 0,0349 \\
Sal comum (2\%) & -- & 0,00035 \\
Nitrato $(0,02 \%)$ & --- & 0,00035 \\
Nitrito $(0,02 \%)$ & 0,0122 & 0,0122 \\
Açúcar $(0,7 \%)$ & &
\end{tabular}

Nota: formulação própria.

Misturou-se a carne, o toucinho e a sacarose num substrato base e 
inoculou-se $1,0 \mathrm{~mL}$ da cultura de Clostridium perfringens tipo A, contendo 6,0 × $10^{3} \mathrm{UFC}$ (contagem obtida após plaqueamento em meio Shahidi, Ferguson Perfringens).

Após a inoculação dos esporos, o substrato foi dividido em duas partes iguais (controle e tratamento) e adicionados nesse último os aditivos (cloreto de sódio, nitrato, nitrito) nas quantidades apresentadas na Tabela 1.

Os substratos de ambos os tratamentos serviram como matéria-prima para a elaboração de lingüiças, embutidas em tripas bovinas, embaladas a vácuo em embalagens de nylon-polietileno, contendo quatro gomos de lingüiça de aproximadamente $50 \mathrm{~g}$ cada. As amostras foram armazenadas em recipiente plástico e mantidas em câmara fria sob temperatura de $5^{\circ} \mathrm{C}$, durante 44 dias.

As lingüiças, antes da análise microbiológica, receberam choque térmico em banho-maria a $80^{\circ} \mathrm{C}$ e resfriamento posterior para temperatura ambiente.

De acordo com a metodologia descrita por SILVA, JUNQUEIRA e SILVEIRA (1997), antes da abertura das embalagens foi realizada a desinfecção com álcool 70\%.

Para a retirada da unidade analítica da lingüiça utilizaram-se pedaços menores de diversos pontos de cada gomo até se obter $25 \mathrm{~g}$. A partir de 40 gomos de lingüiça de cada tratamento realizou-se a contagem global de $C$. perfringens em duplicata, com o preparo de diluições seriadas $\left(10^{-1}, 10^{-2}, 10^{-3}\right)$ das amostras do alimento. Homogeneizouse a unidade analítica em sacos estéreis de polietileno, com solução salina peptonada $(225 \mathrm{~mL})$ em Stomacher para permitir diluição e inoculação no meio de cultura.

Efetuou-se a contagem de esporos viáveis pelo plaqueamento em meio seletivo para Clostridium perfringens tipo A, ágar Shahidi Ferguson Perfringens (SFP) elaborado segundo SHAHIDI e FERGUSON (1971) e suplementado com gema de ovo. As placas foram incubadas por 48 horas a $45^{\circ} \mathrm{C}$ em jarras de anaerobiose.

A partir dos 40 gomos pertencentes ao grupo tratamento foram 
determinadas as concentrações de nitrato e nitrito, em duplicata de $10 \mathrm{~g}$, conforme método descrito por LARA, TAKAHASHI e SILVEIRA (1978).

A análise microbiológica e a determinação dos níveis de nitrato e nitrito foram realizadas em quatro dias consecutivos, com intervalos de dois, quatro, seis, oito e dez dias, completando 44 dias no total.

\section{RESULTADOS E DISCUSSÃO}

Os resultados obtidos no presente estudo estão apresentados nas Tabelas 2 e 3.

TABELA2 - CONTAGEM GLOBAL DE COLÔNIAS DE C. perfringens TIPO A OBTIDAS DAS AMOSTRAS DE LINGÜICCA BOVINA DURANTE A VIDA-DE-PRATELEIRA EM DIFERENTES TRATAMENTOS

\begin{tabular}{|c|c|c|}
\hline \multirow[b]{2}{*}{ Dia } & \multicolumn{2}{|c|}{ Tratamentos } \\
\hline & $\begin{array}{l}\text { Grupo Controle }{ }^{1} \\
\text { (UFC/25 g) }\end{array}$ & $\begin{array}{c}\text { Grupo Tratamento }^{2} \\
\text { (UFC/25 g) }\end{array}$ \\
\hline 1 & $1,0 \times 10^{1}$ & Ausência \\
\hline 2 & $1,0 \times 10^{2}$ & Ausência \\
\hline 3 & $\begin{array}{l}3,0 \times 10^{1} \\
3,5 \times 10^{2}\end{array}$ & Ausência \\
\hline 4 & $1,0 \times 10^{1}$ & Ausência \\
\hline 6 & $3,0 \times 10^{1}$ & Ausência \\
\hline 10 & $1,0 \times 10^{2}$ & Ausência \\
\hline 16 & $1,0 \times 10^{3}$ & Ausência \\
\hline 24 & $\begin{array}{l}3,0 \times 10^{1} \\
8,0 \times 10^{2}\end{array}$ & Ausência \\
\hline $\begin{array}{l}34 \\
44 \\
\end{array}$ & $\begin{array}{l}1,0 \times 10^{2} \\
1,0 \times 10^{3}\end{array}$ & $\begin{array}{l}\text { Ausência } \\
\text { Ausência }\end{array}$ \\
\hline
\end{tabular}

${ }^{1}$ Sem adição do sal de cura.

${ }^{2} \mathrm{Com}$ adição do sal de cura.

UFC = Unidade Formadora de Colônia . 


\section{TABELA 3 - NÍVEIS DE NITRATO E NITRITO (ppm) DETERMINADOS NAS AMOSTRAS DE LINGÜIÇA BOVINA CURADA INOCULADA COM C. perfringens TIPO A EM DIFERENTES DIAS DA VIDA-DE-PRATELEIRA}

\begin{tabular}{cccc}
\hline Dia & Nitrato $(\mathbf{p p m})^{*}$ & Nitrito $(\mathbf{p p m})$ & $\begin{array}{c}\text { Nitrato + Nitrito } \\
\text { (ppm) }\end{array}$ \\
\hline 1 & 200 & 200 & 400 \\
2 & 108,79 & 95,27 & 204,06 \\
3 & 108,74 & 136,65 & 245,39 \\
4 & 101,32 & 93,64 & 194,96 \\
6 & 70,61 & 52,62 & 123,23 \\
10 & 31,56 & 56,41 & 87,97 \\
16 & 13,03 & 43,53 & 56,56 \\
24 & 19,25 & 88,70 & 107,95 \\
34 & 15,39 & 73,87 & 89,26 \\
44 & 12,41 & 58,16 & 70,57 \\
\hline
\end{tabular}

* Nitrato expresso em quantidade residual de nitrito.

De acordo com a legislação brasileira, a tolerância máxima permitida em amostra representativa em relação aos Clostrídios Sulfito Redutores é de $3 \times 10^{3} \mathrm{UFC/g}$ (BRASIL, 2001). A partir da inoculação de $6 \times 10^{3} \mathrm{UFC} / 25 \mathrm{~g}$ nas amostras observou-se que houve crescimento do microrganismo Clostridium perfringens, embora enquadrado nos padrões exigidos pela legislação. Nas amostras que receberam o tratamento (adição do sal de cura) não foi observado crescimento do microrganismo.

Nas análises das amostras preparadas no laboratório (Tabela 2) foram obtidos níveis de nitrato e nitrito acima do permitido pela legislação (BRASIL, 1998a), ou seja, níveis acima de 150 ppm em até quatro dias após a elaboração da lingüiça. Devido a esse fato, os produtos elaborados apresentaram período de redução dos níveis até alcançarem o limite permitido pela legislação específica para posterior comercialização. 
Para FRAZIER e WESTHOFF (1993), algumas linhagens são inibidas por concentração equivalente a $2,5 \%$ de nitrato de sódio. Verificou-se que a cepa de Clostridium perfringens tipo A foi inibida em concentrações inferiores $(0,02 \%)$ de nitrato de sódio.

De acordo com a ICMSF (1980) baixas concentrações de nitrito de sódio produzem em condições adequadas a cor desejável dos produtos cárneos curados, entretanto para o efeito antibacteriano são necessárias concentrações maiores.

Conforme LINDNER (1995) e FEHLHABER e JANETSCHKE (1995) concentrações superiores a 200 ppm de nitrito de sódio exercem ação bacteriostática, especialmente sobre os anaeróbios. Os resultados observados no presente estudo confirmaram o efeito inibitório sobre o Clostridium perfringens tipo $\mathrm{A}$, inclusive em concentração abaixo de 200 ppm de nitrito de sódio. Segundo esses mesmos autores a inibição que ocorre sobre os microrganismos em produtos curados não pode ser explicada somente pela atuação do nitrito. Devem ser considerados também fatores, como o valor de $\mathrm{pH}$, a atividade de água e a adição do sal de cozinha, conforme HERSOM e HULLAND (1985).

Em experimento realizado por PÉREZ-RODRÍGUEZ, BOSCH-BOSCH e GARCÍA MATA (1996), os níveis de nitrato permaneceram constantes até duas semanas de armazenamento divergindo dos resultados obtidos neste trabalho. Verificou-se nível constante somente nos primeiros quatro dias de análise com queda no sexto dia (Tabela 3). Após 18 dias de armazenamento, os autores verificaram que o nitrito foi rapidamente depreciado para nível bastante baixo e constante, restando apenas $50 \%$ da quantidade adicionada após 17 dias. No presente estudo houve declínio do nitrito no quarto dia, que permaneceu em níveis baixos até o 44ํㅡㄹ de armazenamento, restando $21,77 \%$ de nitrito após 17 dias. Em relação a quantidade de nitrato houve queda mais acentuada, restando somente $6,52 \%$ da quantidade total adicionada.

PARDI et al. (1995) citaram que menos de 10\% do nitrito permanece no produto após sete dias. Desta forma, a quantidade de nitrito adquirida pelo consumindor de carnes curadas é menor que a 
quantidade adicionada. Os resultados apresentados na Tabela 3 demonstraram que após seis dias da elaboração da lingüiça, 26,31\% de nitrito de sódio ainda permaneciam no produto.

PINHO et al. (1998) concordam que os resíduos de nitrato e nitrito são detectados em quantidades inferiores às adicionadas ao produto. Níveis altos e baixos foram constatados devido dificuldade de homogeneização de pequenas quantidades dos aditivos na massa.

HERSOM e HULLAND (1985) afirmaram que em relação a coloração característica da carne curada, quantidade mínima de nitrito (30 ppm) é suficiente em presença de ascorbato. Todavia, é necessário 50 ppm para se obter o aroma desejado. Evidenciou-se no experimento que quantidades menores de nitrito do que as citadas ainda conservaram a coloração e o odor característicos do produto (lingüiça).

\title{
4 CONCLUSÃO
}

Pelos resultados obtidos pode-se concluir que na concentração utilizada, o nitrato e o nitrito contribuem para o controle do Clostridium perfringens tipo A em lingüiça.

\begin{abstract}
THE EFFECT OF THE USE OF NITRATE AND NITRATE ON THE INIBITION OF Clostridium perfringens TYPE A ON THE BOVINE CURED SAUSAGE The objective of this study was to verify the efficiency of nitrate and nitrite, during these levels reductions on the shelf life of the bovine cured sausage, inhibiting the development of the microorganism responsable for food poisoning, Clostridium perfringens type $A$. The sausages were elaborated from a basic mixture, which was divided in two samples (control group and treatment group) and inoculated with the culture of $C$. perfringens $\left(6 \times 10^{3} \mathrm{CFU}\right)$. On the group which was aplicated the treatment, the cure salt formulated on the laboratory was added. By microbiological analysis the bacteria was quantified and the residual levels of nitrate and nitrite were determined. The results showed that on the period of shelf life (44 days), C. perfringens didn't growth on the treated samples even in reduced levels, while in the control group the microorganisms have growing up, but within the limits of Brazilian law ( $\left.3 \times 10^{3} \mathrm{CFU}\right)$. The amount of sodium nitrate and sodium nitrite added (200 ppm) shows that a period of reduction of four days before processing were necessarily to get to the limits based on the law (150 ppm). The
\end{abstract}


results showed the nitrate and nitrite were efficient on the inibition of the growth and germination of $C$. perfringens type $A$.

KEY-WORDS: NITRATE; NITRITE; Clostridium perfringens; SAUSAGE.

\section{REFERÊNCIAS}

1 BRASIL. Ministério da Saúde. Agência Nacional de Vigilância Sanitária. Portaria oㅡ 326, de 30 de julho de 1997. Aprova o Regulamento técnico sobre condições higiênico-sanitárias e de boas práticas de fabricação para estabelecimentos produtores/industrializadores de alimentos. Diário Oficial [da] República Federativa do Brasil, Brasília, 01 de agosto de 1997. p. 11.

2 BRASIL. Ministério da Saúde. Agência Nacional de Vigilância Sanitária. Portaria no 1004, de 11 de dezembro de 1998. Aprova o Regulamento técnico sobre atribuição de função de aditivos, aditivos e seus limites máximos de uso para a categoria 8 Carne e Produtos Cárneos. Diário Oficial [da] República Federativa do Brasil, Brasília, 14 de dezembro de 1998a. p. 28-32.

3 BRASIL. Ministério da Saúde. Agência Nacional de Vigilância Sanitária. Portaria no 1002, de 11 de dezembro de 1998. Lista os produtos comercializados no país, enquadrando-os nas sub-categorias que fazem parte da Categoria 8 - Carnes e Produtos Cárneos. Diário Oficial [da] República Federativa do Brasil, Brasília, 14 de dezembro de 1998b. p.28

4 BRASIL. Ministério da Agricultura e do Abastecimento. Secretaria de Defesa Agropecuária. Instrução Normativa $n^{\circ}$ 4 , de 31 de março de 2000. Regulamento técnico de identidade e qualidade das lingüiças. Diário Oficial [da] República Federativa do Brasil, Brasília, 05 de abril de 2000. p.6-10.

5 BRASIL. Ministério da Saúde. Agência Nacional de Vigilância Sanitária. Resolução RDC n 12, de 2 de janeiro de 2001. Regulamento técnico sobre padrões microbiológicos para alimentos. Diário Oficial [da] República Federativa do Brasil, Brasília, 10 de janeiro de 2001. p. 48. 
6 BRASIL. Ministério da Saúde. Fundação Oswaldo Cruz. Instituto Nacional de Controle de Qualidade em Saúde. Laboratório de Microrganismos de Referência. Instruções para reidratação das culturas. Rio de Janeiro, 2005.

7 BRYNESTAD, S.; GRANUM, P.E. Clostridium perfringens and foodborne infections. International Journal of Food Microbiology, v.74, n.3, p.195-202, 2002.

8 CÂMARA, S.A.V. Surtos de toxinfecções alimentares no estado de Mato Grosso do Sul, no período de 1998 2001. Campo Grande, 2002. Monografia (Especialização, Escola de Saúde Pública "Dr. Jorge David Nasser", Gestão em Saúde. Secretaria de Estado de Mato Grosso do Sul). Disponível em: <http://dtr2001.saude.gov.br/bvs/ct/pdf/ sonia_aparecida.pdf> Acesso em: 22 jul. 2005.

9 FEHLHABER, K.; JANETSCHKE, P. Higiene veterinaria de los alimentos. Zaragoza (España): Editorial Acribia, 1995. $669 \mathrm{p}$.

10 FERNANDEZ, A.T.; CASTRO, F.; BECKER, C. M. Avaliação do teor de nitritos e da comercialização de lingüiças clandestinas obtidas no município de Petrópolis / R.J. Escola de Medicina Veterinária. Universidade do Grande Rio João Campos Bonisson. Disponível em: <www.unigranrio.br/ veterinaria/nitritosemlinguicas.doc > Acesso: 10 maio 2005.

11 FRAZIER, W.C.; WESTHOFF, D.C. Microbiología de los alimentos. Zaragoza (España): Editorial Acribia, 1993. $681 \mathrm{p}$.

12 HAYES, P.R. Microbiologia e higiene de los alimentos. Zaragoza (España): Editorial Acribia, 1993. 369 p.

13 HERSOM, A.C.; HULLAND, E.D. Conservas alimenticias. Zaragoza (España): Editorial Acribia, 1985. 451 p.

14 ICMSF. International Commission on Microbiological Specifications for Foods. Ecologia microbiana de los alimentos 1. Factores que afectan a la supervivencia de los microrganismos en los alimentos. Zaragoza (España): Editorial Acribia, 1980. $332 \mathrm{p}$. 
15 JAY, J.M. Microbiologia moderna de los alimentos. Zaragoza (España): Editorial Acribia, 1994. 804 p.

16 LARA, W.H.; TAKAHASHI, M.Y.; SILVEIRA, N. Determinação de nitratos e nitritos em conservas de carne. Revista do Instituto Adolfo Lutz,

v. 38, p.161-166, 1978.

17 LINDNER, E. Toxicologia de los alimentos. Zaragoza (España): Editorial Acribia, 1995. 262 p.

18 ÖZTEKIN, N.; NUTKU, M.S.; ERIM, F.B. Simultaneous determination of nitrite and nitrate in meat products and vegetables by capillary electrophoresis. Food Chemistry, v.76, n.1, p.103-106, 2002.

19 PARDI, C. M.; SANTOS, L.F; SOUZA, E.R; PARDI, H.S. Ciência, higiene e tecnologia da carne. Goiânia: Editora UFG, 1995. 586 p. v. 1.

20 PÉREZ-RODRIGUES, M. L.; BOSCH-BOSCH, N.; GARCIÁMATA, M. Monitoring nitrite and nitrate residues in frankfurters during processing and storage. Meat Science, v.44, n.1, p. 65-73, 1996.

21 PINHO, O.; FERREIRA, I.M.P.L.V.O.; OLIVEIRA, M.B.P.P.; FERREIRA, M.A. FIA evaluation of nitrite and nitrate contents of liver patés. Food Chemistry, v. 62, n.3, p. 359-362, 1998.

22 SHAHIDI, S.A.; FERGUSON, A.R. New quantitative, qualitative, and confirmatory media for rapid analysis of food for Clostridium perfringens. Applied Microbiology, v.21, n.3, p. 500-506, 1971.

23 SILVA, N.; JUNQUEIRA V.C.A.; SILVEIRA, N.F.A. Manual de métodos de análise microbiológica de alimentos. São Paulo: Livraria Varela, 1997.

24 SOARES, A.L.; ODA, S.H.I.; LARA, J.A.F.; YAMASHITA, F.; IDA, E.I.; SHIMOKOMAKI, M. Ingredientes e aditivos para carnes: segurança e inovação. Revista Nacional da Carne, n. 317, v. 22, n. 259, p. 18-22, 2003. 
25 TERRA, N. N. Apontamentos de tecnologia de carnes. São Leopoldo: Ed. UNISINOS, 1998. 216 p. 